\title{
CONCEPTS IN HUMAN NUTRITION AND ANIMAL FEEDING New Reference Values for nutrient intake in Germany, Austria and Switzerland (DACH-reference values)
}

Oléagineux, Corps Gras, Lipides. Volume 8, Numéro 1, 63-5, Janvier - Février 2001, Dossier : Deutsche Gesellschaft für Fettwissenschaft - Association française pour l'étude des corps gras

Auteur(s) : Günther WOLFRAM, Institut für Ernährungswissenschaft, D-85350 FreisingWeilhenstephan, Germany.

Summary : In accordance to their very good collaboration through decades especially at the "3 Countries Meetings" the Nutrition Societies of Germany, Austria and Switzerland (D, A, CH) decided to prepare new Reference Values for nutrient intake as a joint edition in the year 2000 . The Reference Values consist of two parts: Part 1, Nutritive aspects of nutrients. Part 2, Preventive aspect of nutrient and food components. The Reference Values presented should protect almost all individuals of the respective group against potential damage to health from their diet and provide a basis for full functional capacity. In detail recommendations, estimates or guideline values are presented for the different nutrients. Total fat should not exceed $30 \%$ of energy, saturated fatty acids should not provide more than $10 \%$ of energy and polyunsaturated fatty acids $7 \%$ of energy with $n-6$ and $n-3$ fatty acids in a ratio of 5:1. Preventive aspect concern the prophylaxis of nutrition-related diseases.

Keywords : reference values, fat, nutritive and preventive aspects

\section{ARTICLE}

In accordance to their very good collaboration through decades especially at the "3 Countries Meetings" the Nutrition Societies of Germany, Austria and Switzerland (D, A, CH) decided to prepare new reference values for nutrient intake as a joint edition in the year 2000.

The new Reference Values [1] are an amplification of earlier recommendations published in Germany [2]. The nutrient data and energy values serve as the basis for a guide to a wholesome diet and thus are similar to those of equivalent scientific bodies in other countries and those of FAO/WHO. Both the determination of the requirements and the derivation of recommendations correspond to international procedures such as used for the Dietary Reference Intakes (RDI) of 1998 [3]. Argumentations and deviations from recommendations made by other authorities have been explained elsewhere [4]. 
The new reference values and their explanations are presented on 240 pages and the fundamentals of nutritional physiology and biochemistry are supported by nearly 600 references to the literature.

The Reference Values consist of two parts: Part I - Nutritive aspects of nutrients. Part II - Preventive aspects of nutrients and food components.

\section{Nutritive aspects of nutrients}

\section{Objectives of the Reference Values}

Excepting the guidelines for energy intake, recommended values should protect almost all individuals of the respective group against potential damage to health from their diet and provide a basis for full functional capacity. Certain amounts must be added for additional requirements during pregnancy and lactation. It was not intended to consider special dietetic needs, associated with chronic use of drugs or high levels of consumption of coffee, tea, alcohol, etc., with the exception of tobacco and vitamin $\mathrm{C}$. These matters must be left to the decision of the individual physician.

\section{Recommendations, estimated values and guideline values}

Energy and nutrient requirements vary from person to person and from day to day; they are determined by individual factors and depend on a multitude of internal and external influences. Experimentally, they can be determined only in defined and small population groups. The values established are subject to a statistical distribution. In case of a normal distribution (Gaussian curve), the "average requirement" of the group will cover the needs of $50 \%$ of all persons studied while the requirements of remaining $50 \%$ of the group will be above the "average requirement".

Assuming a normal distribution of the average requirements, the levels of the average need for essential nutrients have to be raised by twice the standard deviation to end up with recommendations. In this way, amounts were calculated the intake of which would cover the requirements of nearly $98 \%$ of a population and protect them against health risks from their diet. Except for protein, nutrient requirements do not show a normal statistical distribution. Furthermore, the frequency distribution of the requirements is known only for a few nutrients and for very small population groups. In some cases, data from long-term inquiries into the intake of population groups have to be used. Since the data on the average requirements of the individual nutrients were thus determined by different criteria, the double standard deviation is usually replaced by a safety margin corresponding to $20-30 \%$ of the average requirement whose magnitude is close to that of a hypothetical double standard deviation. The figures determined in this way are given as recommendations.

Such recommendations are made for nutrients listed in Table. Unless stated otherwise, the safety margins added to the average requirements take into account any individual physiological variation and ensure the availability of adequate nutrient stores in the body. Since in many cases, corresponding figures are not available for all age groups, missing data for certain age groups had to be derived by extrapolation.

The human requirements of some nutrients (i.e. biotin, pantothenic acid and a number of trace elements) cannot yet be determined with the required precision. In such cases, estimates were made (Table), which means that the values used were established experimentally but lack adequate 
confirmation, because, the ranges of the available measurements may have been very large for methodological reasons or too few suitable data in humans were available. Where possible, specific figures were given as estimates instead of ranges though for some trace elements (copper, manganese, selenium, chromium, molybdenum) on the basis of available findings, estimates could only be given as ranges.

With regard to the energy supply, the average requirement of the respective population group was chosen as the guideline value because, in central Europe, a warning against overfeeding is given preference over a concern about inadequate energy intake. The guideline values for energy intake cannot be applied directly to individuals since, in addition to sex and body mass, it is predominantly physical activity that has an influence on the energy requirements of individuals. The true energy requirements of individuals can only be established by continuous weight monitoring. Thus, the data given on the energy requirements constitute average values which can be used only as variables, e.g. for calculation of nutrient density or for menu planning in mass catering establishments. They are based on the basal metabolic rate and take into account the known increments to be added for physiological reasons as physical activity levels (PAL-values).

In addition guideline values for orientation purposes are given for the intake of energy water, fat, cholesterol, alcohol, dietary fiber, and fluoride (Table). Estimated minimum requirements are given for water, fluoride and fiber. The intake of fat, cholesterol, alcohol and common salt should be controlled below certain limits.

\section{How to use the Reference Values}

The reference values are dealing with the average needs of groups within the population, to provide reference values for evaluation of the nutrient intake in specific population groups including individuals at different stages of their life and to plan a diet that fulfills the necessary nutritional requirements. In addition the recommendations will help to detect excessive or insufficient intake in risk groups in the population. Most important, the actual status of an individual's nutrient supply should be examined by other methods. The recommendations are not designed to be complied within one day or to act as a strict model for the intake of individual nutrients in a single meal. Since the absorption rate of certain nutrients decreases at very high doses, the recommended intake should be as uniform as possible and not be fulfilled by high doses at long intervals.

The figures given in the tables have been calculated for the median of the respective age group and represent the daily intake per person. In cases of protein and water only, the data are additionally referred to as daily intake per $\mathrm{kg}$ of body weight. This does not imply the true body weight but refers to the rated weight which a person should have according to height (e.g. using Body Mass Index, $\mathrm{BMI})$.

In the references nutrients are given by units of weight. Reference values for energy sources (carbohydrates and fats) and essential fatty acids have been given as percentages of the energy intake. 


\section{Nutrient density}

Considering the dietary situation in Germany (low energy requirements owing to low physical activity), special attention has been given to the ratio between essential nutrients and energy. This problem has been taken into account by the concept of nutrient density, the amount of nutrient per 1 MJ.

\section{Nutrient losses}

The amounts of nutrients recommended refer to the amount still present in the food the time of consumption. For some nutrients, the average losses by cooking and other methods of preparation in the household or in large catering facilities are stated in the explanations. Losses caused by preparation and treatment in the food industries must also be considered.

\section{Undesirable effects of nutrients}

All nutrients including water may be detrimental to health if their intake exceeds certain amounts. In this connection, the fat-soluble vitamins $A$ and $D$ are particularly critical because, at high dosage, they will accumulate in the body and produce characteristic signs of intoxication. Likewise, very high doses of water-soluble vitamins (e.g. vitamin $B_{6}$, folic acid) or minerals (common salt, selenium, fluoride, etc.) may result in undesirable effects. This should be born in mind when over-the-counter vitamin and mineral preparations are used for self-medication. Possible toxicological effects of every nutrient are mentioned and discussed.

\section{Reference values}

\section{Energy}

The guideline values for energy are calculated according to doubly-labelled water measurements. They are valid for individuals with normal body weight and adequate physical activity. In practice to the calculated basal metabolic rate adequate physical activity levels (PAL-Values) are to be added. The energy requirement of an individual must be controlled by following body weight.

\section{Protein}

The recommended intake of protein did not change. The definition of essential and indispensable amino acids is stressed and the protein digestibility corrected amino acid score mentioned. As new indispensable amino acid histidin is introduced.

\section{Fat}

Total fat intake should not exceed $30 \%$ of energy in sedentary individuals and can reach $35 \%$ of energy in physically active individuals. Saturated fatty acids should provide no more than $10 \%$ of energy, polyunsaturated fatty acids can reach $7 \%$ of energy and even $10 \%$ of energy, when intakes of saturated fatty acids and/or cholesterol are high. The ratio of linoleic ( $n-6)$ to alpha-linolenic acid ( $n$ 3) should reach 5:1. Monounsaturated fatty acids may provide the difference to the recommended amount of total fat. 
Trans fatty acids should be below $1 \%$ of energy. Reference Values for essential fatty acids should be: $2.5 \%$ of energy for linoleic acid ( $n-6)$ and $0.5 \%$ of energy for alpha-linolenic acid ( $n-3)$.

\section{Carbohydrates and dietary fibers}

The decrease of nutrient density by a high sucrose intake is discussed. The guideline value of dietary fiber is unchanged at $30 \mathrm{~g}$ day at least.

\section{Alcohol}

The first time a guideline value for alcohol of $20 \mathrm{~g}$ alcohol per day for the healthy man and of $10 \mathrm{~g}$ alcohol per day for the healthy women is stated. The different negative effects of an higher alcohol intake are discussed.

\section{Vitamins}

Within the vitamins the reference values for vitamin $E$, folic acid, and vitamin $C$ are increased, for vitamin $B_{1}, B_{2}, B_{6}$ and niacin are decreased and for vitamin $A, D, K$, pantothenic acid, biotin and vitamin $B_{12}$ are unchanged with respect to the older reference values [2].

\section{Minerals and trace elements}

The reference values for calcium and magnesium and that for zinc are increased. The reference values for Iron and lodine are unchanged and for some other trace elements are precised.

\section{Preventive aspects of nutrients and food components}

Reference values for nutrient intake are also guided by health aspects in the sense of the prevention of nutrition-related diseases. The avoidance of excessive intake (particularly detrimental in the case of energy, fat, alcohol, cholesterol, purines and common salt) is already a very important preventive measure. For detailed figures, one is referred to the Nutrition Reports of the German Nutrition Society and the National Food Consumption Study [5].

At present, special attention is payed to the antioxidative effects of vitamins $C$ and $E$ and of carotenoids in the prevention of diseases. However the present state of knowledge does not justify specific recommendations. At the international level, comprehensive work has been done on the influence of the vitamins $\mathrm{E}, \mathrm{C}$ and beta-carotene on health, performance and life expectancy. As a result there is no evidence for preventive effects of vitamin $E, C$ or beta-carotene against myocardial infarction or cancer, but there are several studies showing the protective effect of a wholesome nutrition. The detrimental effect of high supplements of beta-carotene in smokers needs special attention. The beneficial effect of folic acid against neural tube defect and vitamin $\mathrm{K}$ against osteoporosis are discussed. Based on this material, effective strategies have been developed for prevention, intervention and therapy. The essence of these has been incorporated into the present recommendations. By ensuring an wholesome diet, full implementation of the present reference values on nutrient intake may effectively contribute to the prevention of diseases. 


\section{REFERENCES}

1. Deutsche Gesellschaft für Ernährung, Österreichische Gesellschaft für Ernährung, Schweizerische Gesellschaft für Ernährungsforschung, Schweizerische Vereinigung für Ernährung (Hrsg.) (2000). DACH-Referenzwerte für die Nährstoffzufuhr. Umschau/ Braus, 1. Auflage, Frankfurt am Main.

2. Deutsche Gesellschaft für Ernährung - Ausschuss für Nahrungsbedarf (Hrsg.) (1991). Empfehlungen für die Nährstoffzufuhr. Umschau Verlag, Frankfurt am Main.

3. Food and Nutrition Board/Institute of Medicine (1998). Dietary Reference Intakes for Thiamin, Riboflavin, Niacin, Vitamin $B_{6}$, Folate, Vitamin $B_{12}$, Pantothenic Acid, Biotin and Choline. Washington D.C. : National Academy Press.

4. Referenzwerte für die Nährstoffzufuhr der DGE, ÖGE, SGE und SVE (2000). 1. Auflage. Auflistung und Kommentar der Neuerungen. Ernährungs-Umschau, 47: 80-5.

5. German Nutrition Society (2000). Nutrition Report 2000 Druckerei Henrich, Frankfurt/Main.

Illustrations

Table. Recommendations, estimated values and guideline values for men 19-25 years old (amounts per day). From DACH -References values [1]

\begin{tabular}{lr|lr|lr}
\multicolumn{2}{l|}{ Recommendations } & \multicolumn{2}{|c|}{ Estimated values } & \multicolumn{2}{c}{ Guideline values } \\
\hline Protein & $59 \mathrm{~g}$ & alpha-Linolenic acid & $0.5 \%$ & Energy & $2,500 \mathrm{kcal}$ \\
Linoleic acid & $2.5 \%$ & beta-Carotene & $2-4 \mathrm{mg}$ & Fat & $30 \%$ of energy \\
Vitamin A & $1.0 \mathrm{mg}$ & Vitamin E & $15 \mathrm{mg}$ & Cholesterol & $300 \mathrm{mg}$ \\
Vitamin D & $5 \mathrm{mug}$ & Vitamin K & $70 \mathrm{mug}$ & Carbohydrates & $>50 \%$ \\
Thiamin & $1.3 \mathrm{mg}$ & Pantothenic acid & $6 \mathrm{mg}$ & Fiber & $>30 \mathrm{~g}$ \\
Riboflavin & $1.5 \mathrm{mg}$ & Biotin & $30-60 \mathrm{mug}$ & Alcohol & $20 \mathrm{~g}$ \\
Niacin & $17 \mathrm{mg}$ & Sodium & $550 \mathrm{mg}$ & Water & $2,700 \mathrm{ml}$ \\
Vitamin $\mathrm{B}_{\mathrm{E}}$ & $1.5 \mathrm{mg}$ & Chloride & $830 \mathrm{mg}$ & Fluoride & $3.8 \mathrm{mg}$ \\
Folic acid & $400 \mathrm{mug}$ & Potassium & $2,000 \mathrm{mg}$ & & \\
Vitamin $\mathrm{B}_{12}$ & $3.0 \mathrm{mug}$ & Selen & $30-70 \mathrm{mug}$ & & \\
Vitamin C & $100 \mathrm{mg}$ & Copper & $1.0-1.5 \mathrm{mg}$ & & \\
Cakium & $1,000 \mathrm{mg}$ & Manganese & $2.0-5.0 \mathrm{mg}$ & & \\
Phosphorus & $700 \mathrm{mg}$ & Chromium & $30-100 \mathrm{mug}$ & & \\
Magnesium & $400 \mathrm{mg}$ & Molybdenum & $50-100 \mathrm{mug}$ & & \\
Iron & $10 \mathrm{mg}$ & & & \\
lodine & $200 \mathrm{mug}$ & & & \\
Zinc & $10 \mathrm{mg}$ & & &
\end{tabular}

